OPEN ACCESS

Edited by:

David Vaudry,

Institut National de la Santé et de la

Recherche Médicale (INSERM),

France

Reviewed by:

Victor May,

The University of Vermont,

United States

Hirokazu Ohtaki,

Showa University, Japan

Shinsuke Matsuzaki,

Wakayama Medical University, Japan

*Correspondence:

Hitoshi Hashimoto

hasimoto@phs.osaka-u.ac.jp

Yukio Ago

yukioago@hiroshima-u.ac.jp

tThese authors have contributed equally to this work

Specialty section: This article was submitted to

Neuroendocrine Science, a section of the journal

Frontiers in Neuroscience

Received: 10 January 2020 Accepted: 27 April 2020

Published: 04 June 2020

Citation:

Takeuchi S, Kawanai T, Yamauchi R, Chen L, Miyaoka T,

Yamada M, Asano S, Hayata-Takano A, Nakazawa T, Yano K, Horiguchi N, Nakagawa S,

Takuma K, Waschek JA, Hashimoto $H$ and Ago Y (2020) Activation of the

VPAC2 Receptor Impairs Axon

Outgrowth and Decreases Dendritic Arborization in Mouse Cortical

Neurons by a PKA-Dependent Mechanism. Front. Neurosci. 14:521. doi: 10.3389/fnins.2020.00521

\section{Activation of the VPAC2 Receptor Impairs Axon Outgrowth and Decreases Dendritic Arborization in Mouse Cortical Neurons by a PKA-Dependent Mechanism}

Shuto Takeuchi ${ }^{1+}$, Takuya Kawanai ${ }^{1+}$, Ryosuke Yamauchi ${ }^{1+}$, Lu Chen ${ }^{2}$, Tatsunori Miyaoka², Mei Yamada², Satoshi Asano ${ }^{3}$, Atsuko Hayata-Takano 1,4, Takanobu Nakazawa ${ }^{1,5}$, Koji Yano ${ }^{6}$, Naotaka Horiguchi ${ }^{6}$, Shinsaku Nakagawa ${ }^{2,7,8}$, Kazuhiro Takuma ${ }^{4,5}$, James A. Waschek ${ }^{9}$, Hitoshi Hashimoto ${ }^{1,4,10,11,12 *}$ and Yukio Ago ${ }^{2,3,7,8 *}$

\begin{abstract}
1 Laboratory of Molecular Neuropharmacology, Graduate School of Pharmaceutical Sciences, Osaka University, Suita, Japan, ${ }^{2}$ Laboratory of Biopharmaceutics, Graduate School of Pharmaceutical Sciences, Osaka University, Suita, Japan, ${ }^{3}$ Department of Cellular and Molecular Pharmacology, Graduate School of Biomedical and Health Sciences, Hiroshima University, Hiroshima, Japan, ${ }^{4}$ Molecular Research Center for Children's Mental Development, United Graduate School of Child Development, Osaka University, Kanazawa University, Hamamatsu University School of Medicine, Chiba University and University of Fukui, Suita, Japan, ${ }^{5}$ Department of Pharmacology, Graduate School of Dentistry, Osaka University, Suita, Japan, ${ }^{6}$ Neuroscience Department, Drug Discovery and Disease Research Laboratory, Shionogi Pharmaceutical Research Center, Shionogi \& Co., Ltd., Toyonaka, Japan, ${ }^{7}$ Laboratory of Innovative Food Science, Graduate School of Pharmaceutical Sciences, Osaka University, Suita, Japan, ${ }^{8}$ Global Center for Medical Engineering and Informatics, Osaka University, Suita, Japan, ${ }^{9}$ Department of Psychiatry and Biobehavioral Sciences, David Geffen School of Medicine, Semel Institute for Neuroscience and Human Behavior, University of California, Los Angeles, Los Angeles, CA, United States, ${ }^{10}$ Division of Bioscience, Institute for Datability Science, Osaka University, Suita, Japan, ${ }^{11}$ Transdimensional Life Imaging Division, Institute for Open and Transdisciplinary Research Initiatives, Osaka University, Suita, Japan, ${ }^{12}$ Department of Molecular Pharmaceutical Science, Graduate School of Medicine, Osaka University, Suita, Japan
\end{abstract}

Clinical studies have shown that microduplications at 7q36.3, containing VIPR2, confer significant risk for schizophrenia and autism spectrum disorder (ASD). VIPR2 gene encodes the VPAC2 receptor for vasoactive intestinal peptide (VIP) and pituitary adenylate cyclase-activating polypeptide (PACAP). Lymphocytes from patients with these mutations exhibited higher VIPR2 gene expression and VIP-induced CAMP responsiveness, but mechanisms by which overactive VPAC2 signaling may lead to these psychiatric disorders are unknown. We have previously found that repeated administration of a selective VPAC2 receptor agonist Ro25-1553 in the mouse during early postnatal development caused synaptic alterations in the prefrontal cortex and sensorimotor gating deficits. In this study, we aimed to clarify the effects of VPAC2 receptor activation on neurite outgrowth in cultured primary mouse cortical neurons. Ro25-1553 and VIP caused reductions in total numbers and lengths of both neuronal dendrites and axons, while PACAP38 facilitated elongation of dendrites, but not axons. These effects of Ro25-1553 and VIP were blocked by a VPAC2 receptor antagonist PG99-465 and abolished in VPAC2 receptor-deficient mice. Additionally, Ro25-1553induced decreases in axon and dendritic outgrowth in wild-type mice were blocked by a protein kinase A (PKA) inhibitor H89, but not by a PKC inhibitor GF109203X or a mitogen-activated protein kinase (MAPK) kinase (MEK) inhibitor U0126. PACAP38- 
induced facilitation of dendritic outgrowth was blocked by U0126. These results suggest that activation of the VPAC2 receptor impairs neurite outgrowth and decreases branching of cortical neurons by a PKA-dependent mechanism. These findings also imply that the VIPR2-linkage to mental health disorders may be due in part to deficits in neuronal maturation induced by VPAC2 receptor overactivation.

Keywords: VPAC2 receptor, psychiatric disorders, cortical neurons, axon, dendrite

\section{INTRODUCTION}

Accumulating evidence indicates that a number of rare copy number variants (CNVs), including both deletions and duplications, have been strongly associated with schizophrenia and neurodevelopmental disorders such as autism spectrum disorder (ASD) (Sullivan et al., 2012; Foley et al., 2017; Deshpande and Weiss, 2018; Vicari et al., 2019). Among the most highly penetrant genetic risk factors for neuropsychiatric disorders, clinical studies have shown that microduplications at 7q36.3, containing VIPR2, confer significant risk for schizophrenia (Levinson et al., 2011; Vacic et al., 2011; Yuan et al., 2014; Li et al., 2016; Marshall et al., 2017) and ASD (Vacic et al., 2011; Firouzabadi et al., 2017). VIPR2 encodes VPAC2, a seven transmembrane heterotrimeric $G$ protein-coupled receptor (Gs) that binds two homologous neuropeptides with high affinity, vasoactive intestinal peptide (VIP) and pituitary adenylate cyclase-activating polypeptide (PACAP). Lymphocytes from patients with these microduplications exhibited higher VIPR2 gene expression and VIP responsiveness (cAMP induction) (Vacic et al., 2011), demonstrating the functional significance of the microduplications. Additionally, the blood concentration of VIP, but not PACAP, was higher in children with ASD compared to healthy control subjects (Nelson et al., 2001). These suggest that overactivation of the VPAC2 receptor signaling is involved in the etiology of schizophrenia and ASD. We previously found that repeated administration of the selective VPAC2 receptor agonist Ro25-1553 in the mouse during early postnatal development caused prepulse inhibition deficits and reductions in synaptic proteins synaptophysin and postsynaptic density protein 95 (PSD-95) in the prefrontal cortex, but not in the hippocampus (Ago et al., 2015). Recently, Tian et al. (2019) have developed a conditional human VIPR2 CNV bacterial artificial chromosome (BAC) transgenic (hVIPR2-BAC tg) mouse model of VIPR2 CNV, and they reported that hVIPR2-BAC tg mice showed cognitive, sensorimotor gating, and social behavioral deficits and decrease in the complexity of dendritic arborization of the striatal spiny projection neurons. Additionally, VPAC2 receptor knockout mice have abnormal dendritic morphology of the prefrontal cortex neurons, but not basolateral amygdala neurons (Ago et al., 2017). These findings suggest that the VPAC2 receptor plays an important role in the regulation of the dendritic morphology and overactivation of the VPAC2 receptor might impair neural development in the brain.

Both PACAP and VIP have been known to regulate cell proliferation, differentiation, survival, maturation, neurite outgrowth, and expression of trophic factors (see review: Waschek, 1996, 2002; Muller et al., 2006; Falluel-Morel et al.,
2007; Hill, 2007; Vaudry et al., 2009; Harmar et al., 2012). In particular, our and other studies have shown that PACAP and VIP promote neurite outgrowth in sympathetic precursors ( $\mathrm{Lu}$ et al., 1998; DiCicco-Bloom et al., 2000; Nicot and DiCiccoBloom, 2001; Suh et al., 2001), pheochromocytoma PC12 cells (Deutsch and Sun, 1992; Hernandez et al., 1995; Lazarovici et al., 1998; Vaudry et al., 2002; Sakai et al., 2004; Manecka et al., 2013), neuroblastoma NB-OK, Neuro2a and SH-SY5Y cells (Deutsch et al., 1993; Héraud et al., 2004; Monaghan et al., 2008; Kambe and Miyata, 2012) and primary cultured hippocampal neurons (Leemhuis et al., 2007; Kambe and Miyata, 2012; Ogata et al., 2015), cerebellar granule cells (Gonzalez et al., 1997; Falluel-Morel et al., 2005), dorsal root ganglion cells (White and Mansfield, 1996; White et al., 2000), and trigeminal ganglion cells (Fukiage et al., 2007). In contrast, both PACAP and VIP inhibited the induction of dendritic growth by bone morphogenetic protein-7 (BMP-7) in primary cultured sympathetic neurons (Drahushuk et al., 2002). This highlights a hierarchal reversal of action that may occur in the presence of a patterning molecule. Opposing activities of PACAP on neural precursors have also been observed in other contexts. For instance, the action of PACAP on embryonic rat cortical precursors switches from antimitotic to promitotic depending on the presence or absence of specific PACAP receptor splice variants (Nicot and DiCiccoBloom, 2001). The switch to promitotic action appeared to occur by a mechanism that involves recruitment of the phospholipase $\mathrm{C}$ pathway. Overall, these findings suggest that neuropeptides PACAP and VIP can exhibit tissue- or cell-type-specific effects due to the expression level and pattern of the PACAP receptor subtypes and splice variants, and the presence or absence of growth and patterning factors. In most cases, however, the precise receptors and intracellular signaling mechanisms that account for this remain unknown.

Here we aimed to investigate the effects of the VPAC2 receptor activation by using Ro25-1553 and VPAC2 receptor-null mice on axon and dendritic outgrowth in primary cultured mouse cortical neurons. We also compare the effects of Ro25-1553 with those of VIP and PACAP. Furthermore, we examined the intracellular signaling pathways involved in the effects of Ro251553 and PACAP.

\section{ANIMALS AND METHODS}

\section{Animals and Materials}

The pregnant ICR (CD1) mice at 16 days of gestation were purchased from Japan SLC, Inc (Hamamatsu, Japan). The generation of VPAC2 receptor deficient mice using gene targeting 
has been previously reported (Harmar et al., 2002). VPAC2 receptor homozygous knockout mice and littermate wild-type mice (C57BL/6 strain) used here were obtained by crossing with VPAC2 receptor heterozygous mice (Ago et al., 2017). Mice were housed in clear cages in groups of 3-5 animals under controlled environmental conditions $\left(22 \pm 1^{\circ} \mathrm{C} ; 50 \pm 10 \%\right.$ relative humidity; a 12-h light-dark cycle, lights on at $0800 \mathrm{~h}$; food and water ad libitum). Ro25-1553, VIP, and PACAP38 were purchased from Peptide Institute, Inc (Osaka, Japan). H89, GF109203X, and U0126 were purchased from Sigma-Aldrich (St. Louis, MO, United States). PG99-465 was purchased from Bachem (Bubendorf, Switzerland). The concentrations of the peptides and compounds used here were selected based on previous studies (Gourlet et al., 1997; Drahushuk et al., 2002; Leemhuis et al., 2007; Ogata et al., 2015). Primary neuronal cultures prepared from CD1 mice were used in most experiments (Figures 1-4, 6). Wild-type and VPAC2 receptor deficient C57BL/6 mice were used to examine the VPAC2 receptormediated effects of Ro25-1553 (Figure 5).

\section{Preparation of Primary Neuronal Cultures}

Primary neuronal cultures were prepared from cerebral cortices of 16-day-old embryonic mice as previously described (Takuma et al., 2009; Kawanai et al., 2016). In brief, cerebral cortices were dissected from embryonic mice, sliced at a thickness of 0.5$1 \mathrm{~mm}$ with a razor blade under ice cold conditions $\left(1-4^{\circ} \mathrm{C}\right)$, and incubated with $0.05 \%$ Trypsin-EDTA-4Na under a humidified atmosphere of $95 \%$ air $/ 5 \% \mathrm{CO}_{2}$ at $37^{\circ} \mathrm{C}$ for $15 \mathrm{~min}$. Tissues were then mechanically dissociated with a fire-polished Pasteur pipette in Neurobasal ${ }^{\mathrm{TM}}$ medium containing $2 \%$ B27 supplement, $2 \mathrm{mM}$ L-glutamine, 50 units $/ \mathrm{mL}$ penicillin, and $50 \mu \mathrm{g} / \mathrm{mL}$ streptomycin. Cells were then plated at a density of $1 \times 10^{4}$ cells $/ \mathrm{cm}^{2}$ on glass coverslips in 24-well tissue culture plates, which were coated with $20 \mu \mathrm{g} / \mathrm{mL}$ of poly-L-lysine (day 0 ). Cell cultures were kept at $37^{\circ} \mathrm{C}$ in a $95 \%$ air $/ 5 \% \mathrm{CO}_{2}$ humidified incubator. Cells were treated with Ro25-1553, VIP, or PACAP38 at 1 day in vitro (DIV) until 3, 7, or 14 DIV. During the experiments, the culture medium including freshly prepared compounds and peptides at the same concentration as 1 DIV was replaced every 3 days.

\section{Morphological Analysis}

Cells were fixed with $4 \%$ paraformaldehyde for $10 \mathrm{~min}$ at $4^{\circ} \mathrm{C}$, and incubated with $0.2 \%$ Triton $\mathrm{X}-100$ in $\mathrm{Ca}^{2+}, \mathrm{Mg}^{2+}$-free phosphate buffered saline (PBS, $\mathrm{pH} 7.2$ ) for $5 \mathrm{~min}$ at room temperature. After blocking with $1 \%$ bovine serum albumin (BSA)/PBS for $30 \mathrm{~min}$, they were incubated with a chicken polyclonal anti-MAP2 antibody (1:5000; Cat\# ab5392, Abcam, Cambridge, United Kingdom; RRID:AB_2138153) and a mouse monoclonal anti-Neurofilament $\mathrm{H} \& \mathrm{M}$, Phosphorylated antibody (1:500; Cat\# SMI-310, Covance Japan, Tokyo, Japan; RRID:AB_448147) at $4^{\circ} \mathrm{C}$ overnight. After washing with PBS, the cells were incubated with species-specific fluorophore-conjugated secondary antibodies (1:200; Alexa 488conjugated anti-chicken IgY (Cat\# A32931, RRID:AB_2762843) and Alexa 594-conjugated anti-mouse IgG (Cat\# A-11005,
RRID:AB_2534073), Thermo Fisher Scientific) for $2 \mathrm{~h}$ at room temperature. The cells were washed with PBS and mounted using the ProLong ${ }^{\mathrm{TM}}$ Gold antifade reagent (Thermo Fisher Scientific). Digitized images were obtained with an upright light microscope with a cooled CCD digital camera system (Axio Imager. M2/AxioCam MRc5; Carl Zeiss, Jena, Germany). In this study, phosphorylated neurofilaments ( $\mathrm{pNF}$ )-positive neurites were classified morphologically as axons, and MAP2-positive and pNF-negative neurites were classified as dendrites. We exclude the cells that did not have axons or dendrites from further analysis. Additionally, a few complex overlapping neurons were not measured. Then, 10-20 neurons in each experiment were randomly selected by an observer blind to the treatment. Each experiment was independently repeated three times. The axon and all dendrites of each neuron were manually traced with Neurolucida software (Version 11; MBF Bioscience, Inc., Williston, VT, United States). The axon length, total number of dendrites (total number of terminal dendrite branches), total length of all dendrites, and dendritic complexity in each neuron were calculated from the traced neurites using Neurolucida. Dendritic complexity was assessed by measuring the lengths of dendrites and counting the number of branch points in each branch order. The dendritic complexity index was calculated from: (sum of the terminal orders + number of terminals) $\times$ (total dendritic length/number of primary dendrites) (Pillai et al., 2012). Terminal order indicates the number of sister branches emanating from the dendritic segment between a particular terminal tip and cell body.

\section{RT-PCR}

Total RNAs from cultured cells were isolated using the SV Total RNA isolation system (Promega, Madison, WI, United States) according to the manufacturer's instructions. The total RNAs were reverse transcribed with Superscript III (Thermo Fisher Scientific, Waltham, MA, United States). RT-PCR was performed with GoTaq ${ }^{\circledR}$ Green Master Mix (Promega) using Applied Biosystems $^{\text {TM }}$ Veriti $^{\text {TM }}$ 96-Well Thermal Cycler. The following primers were used: 5'-ATGAGTCTTCCCCAGGTTG-3' (forward) and 5' -ACCGACAGGTAGTAATAATCC-3' (reverse) for the PAC1 receptor; 5'-AGTGAAGACCGGCTACACCA-3' (forward) and 5'-TCGACCAGCAGCCAGAAGAA-3' (reverse) for the VPAC1 receptor; 5'-ATGGACAGCAACTCGCCTC TCTTTAG-3' (forward) and 5'-GGAAGGAACCAACACATAA CTCAAACAG-3' (reverse) for the VPAC2 receptor; $5^{\prime}$-AC CACAGTCCATGCCATCAC-3' (forward) and 5' ${ }^{\prime}$-TCCA CCACCCTGTTGCTGTA-3' (reverse) for GAPDH. PCR was performed for 40 cycles at $95^{\circ} \mathrm{C}$ for $30 \mathrm{~s} ; 55^{\circ} \mathrm{C}$ for $30 \mathrm{~s}$; and $72^{\circ} \mathrm{C}$ for $30 \mathrm{~s}$.

\section{Statistical Analysis}

All results are presented as the mean \pm standard deviation (SD). Statistical analyses were performed using Statview (SAS Institute Japan Ltd., Tokyo, Japan), and significant differences determined by one- or two-way ANOVA followed by the Tukey-Kramer test. The threshold for statistical significance was defined as $P<0.05$. 


\section{A VIPIPACAP receptor expression}

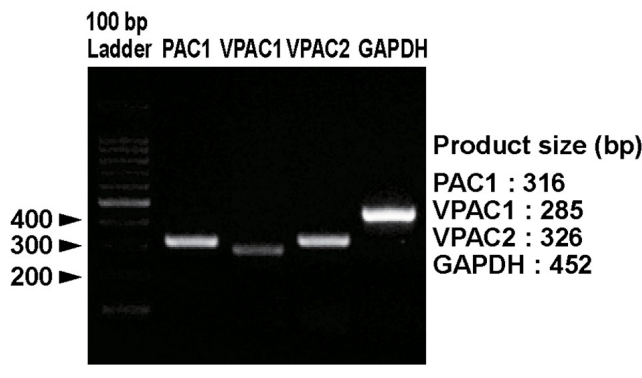

B Representative images

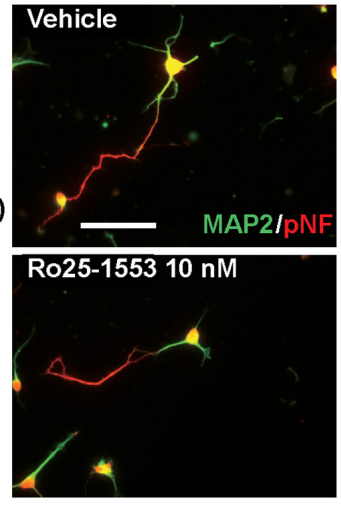

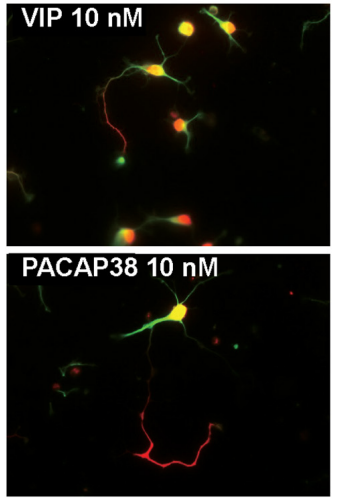

C Axon length

VIP

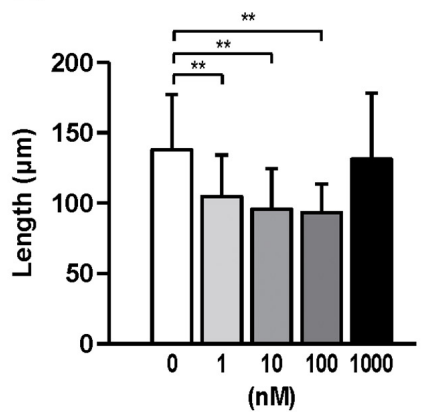

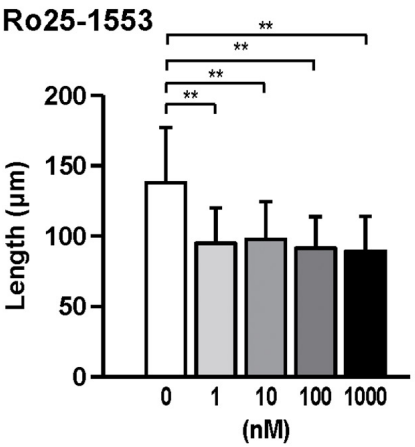

PACAP

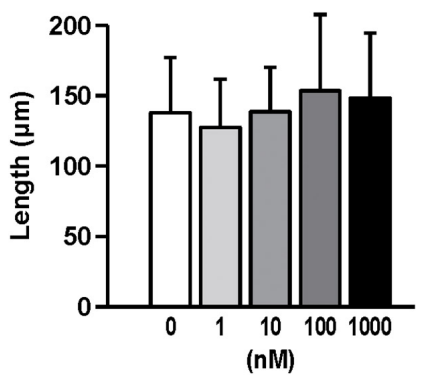

FIGURE 1 | Effects of Ro25-1553, VIP, and PACAP on axon outgrowth in cultured cortical neurons. (A) RT-PCR analysis showed that all VIP/PACAP receptors PAC1, VPAC1, and VPAC2 were expressed in primary cultured cortical neurons. (B) Representative pNF- and MAP2-immunostained images of cultured cortical neurons are shown. Cells were cultured with Ro25-1553 (10 nM), VIP (10 nM), or PACAP38 (10 nM) for 3 days in vitro and double-immunostained for pNF (red) and MAP2 (green). Scale bar, $50 \mu \mathrm{m}$. (C) Quantitative analysis of changes in axon length was shown. VIP $\left(F_{4,215}=16.542, P<0.0001\right)$ and Ro25-1553

$\left(F_{4,215}=25.257, P<0.0001\right)$, but not PACAP $\left(F_{4,215}=2.383, P>0.05\right)$, reduced the axon length. Values represent mean \pm SD of $40-60$ neurons from three independent experiments. ${ }^{\star \star} P<0.01$ vs. control.

\section{RESULTS}

Figure 1A shows the gel images for RT-PCR for PAC1, VPAC1, VPAC2 receptors, and GAPDH, indicating that all VIP/PACAP receptors are expressed in primary cultured cortical neurons. Then, we examined the effects of VIP, Ro25-1553, and PACAP on axon and dendritic outgrowth in cultured cortical neurons. Figure 1B shows the representative pNF- and MAP2immunostained images of primary cultured cortical neurons treated with Ro25-1553 (10 nM), a selective VPAC2 receptor agonist, VIP $(10 \mathrm{nM})$, and PACAP $(10 \mathrm{nM})$ for 3 days in vitro (DIV). Treatment with VIP (1, 10, and $100 \mathrm{nM}$ ) and Ro251553 (1-1000 nM) for 3 DIV significantly reduced axon length (Figure 1C). PACAP at doses used here (1-1000 nM) did not affect the axon length.

Figure 2 shows the effects of VIP on dendritic outgrowth. Primary cortical neurons were cultured with VIP for 14 DIV. Representative MAP2-immunostained images of neurons treated with different concentrations of VIP at 7 and 14 DIV are shown. With longer periods in culture, overall increase in dendrite extension and branching were observed. Quantitative morphological analysis revealed that VIP at doses of 1-100 nM, but not $1000 \mathrm{nM}$, decreased the total numbers and length of dendrites, and dendritic complexity for 3 to $14 \mathrm{DIV}$.

Figure 3 shows the effects of Ro25-1553 on dendritic outgrowth. Primary cortical neurons were cultured with Ro251553 for 14 DIV. Representative MAP2-immunostained images of neurons treated with different concentrations of Ro25-1553 at 7 and 14 DIV are shown. Quantitative morphological analysis revealed that Ro25-1553 at doses of 1-1000 nM decreased the total numbers and length of dendrites, and dendritic complexity for 3 to 14 DIV.

Figure 4 shows the effects of PACAP on dendritic outgrowth. Primary cortical neurons were cultured with PACAP for 7 DIV. Representative MAP2-immunostained images of neurons treated with different concentrations of PACAP at 7 DIV are shown. Quantitative morphological analysis revealed that PACAP (1$1000 \mathrm{nM}$ ) dose-dependently increased the total numbers and length of dendrites, and dendritic complexity for 3 to 7 DIV.

Figure 5 shows the involvement of the VPAC2 receptor in the inhibitory effects of Ro25-1553 and VIP on axon and dendritic outgrowth. Pretreatment with PG99-465 (100 nM), a VPAC2 receptor antagonist, blocked Ro25-1553 (10 nM)- and VIP (10 nM)-induced reductions in axon length, total numbers 

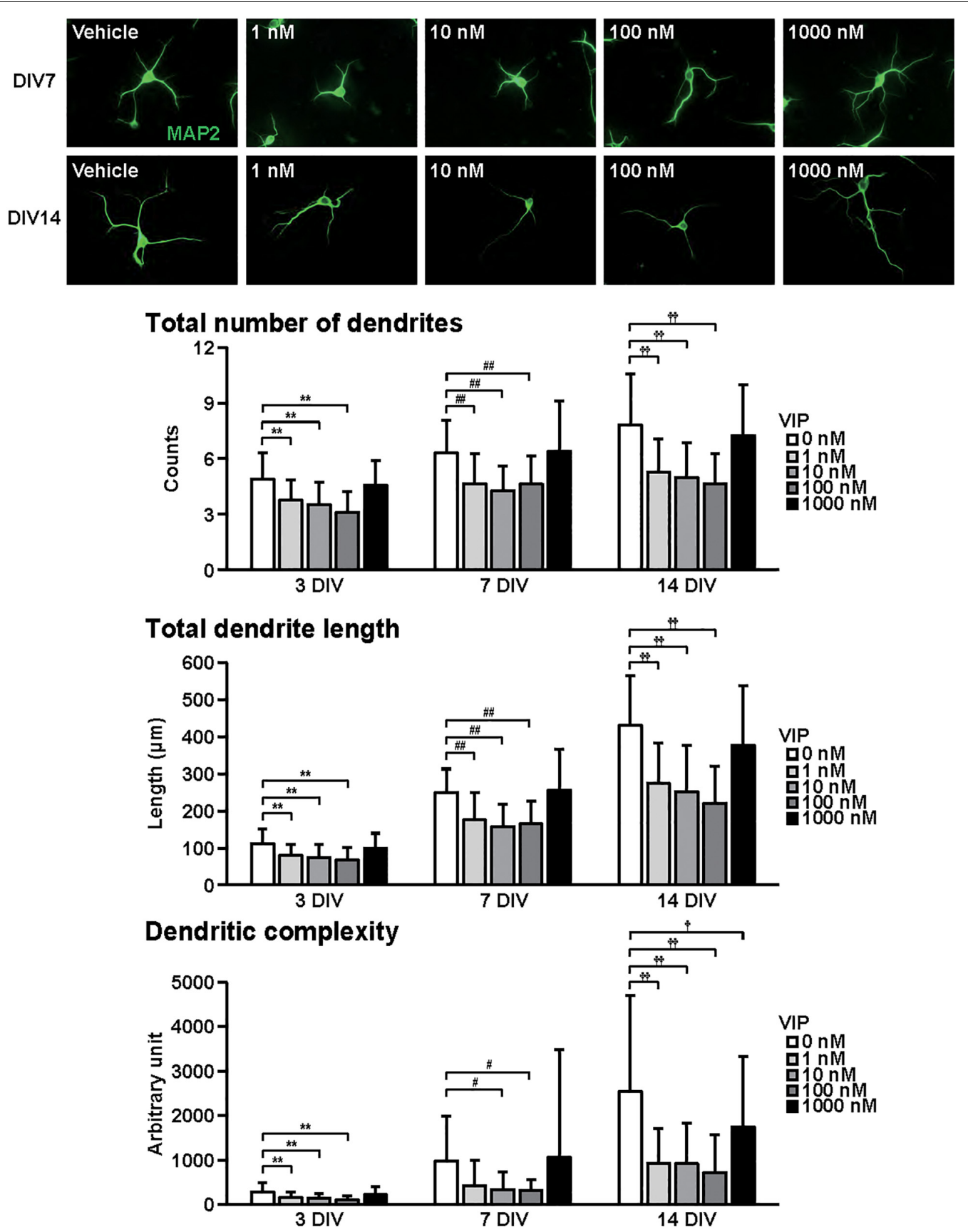

FIGURE 2 | Effects of VIP on dendritic outgrowth in cultured cortical neurons. Representative MAP2 (green)-immunostained images of neurons cultured with VIP (1-1000 nM) for 7 to 14 days in vitro (DIV) are shown. Quantitative analysis of dendritic morphology at 3 (Figure 1B), 7 , and 14 DIV revealed that VIP significantly decreased the total numbers (main effects: $F_{2,805}=75.487, P<0.0001$ for time, $F_{4,805}=52.424, P<0.0001$ for treatment; interaction: $F_{8,805}=2.556, P<0.01$ ) and length (main effects: $F_{2,805}=374.760, P<0.0001$ for time, $F_{4,805}=51.272, P<0.0001$ for treatment; interaction: $F_{8,805}=8.563, P<0.0001$ ) of dendrites, and dendritic complexity (main effects: $F_{2,805}=76.423, P<0.0001$ for time, $F_{4,805}=20.616, P<0.0001$ for treatment; interaction: $F_{8,805}=5.856, P<0.0001$ ). Values represent mean $\pm \mathrm{SD}$ of $40-60$ neurons from three independent experiments. ${ }^{\star \star} P<0.01,{ }^{\#} P<0.05,{ }^{\# \#} P<0.01,{ }^{\dagger} P<0.05,{ }^{\dagger \dagger} P<0.01$ vs. control.

and length of dendrites, and dendritic complexity (Figure 5A). Additionally, Ro25-1553-induced reductions in axon length, total numbers and length of dendrites, and dendritic complexity were abolished in cortical neurons derived from VPAC2 receptor knockout mice (Figure 5B).
Figure 6 shows the signaling pathway involved in the effects of Ro25-1553 and PACAP on neurite outgrowth. Pretreatment with a PKA inhibitor H89 (1 $\mu \mathrm{M})$, but not a PKC inhibitor GF109203X (1 $\mu \mathrm{M})$ or a MEK inhibitor U0126 (1 $\mu \mathrm{M})$, blocked Ro25-1553 (10 nM)-induced reductions in axon length, total 

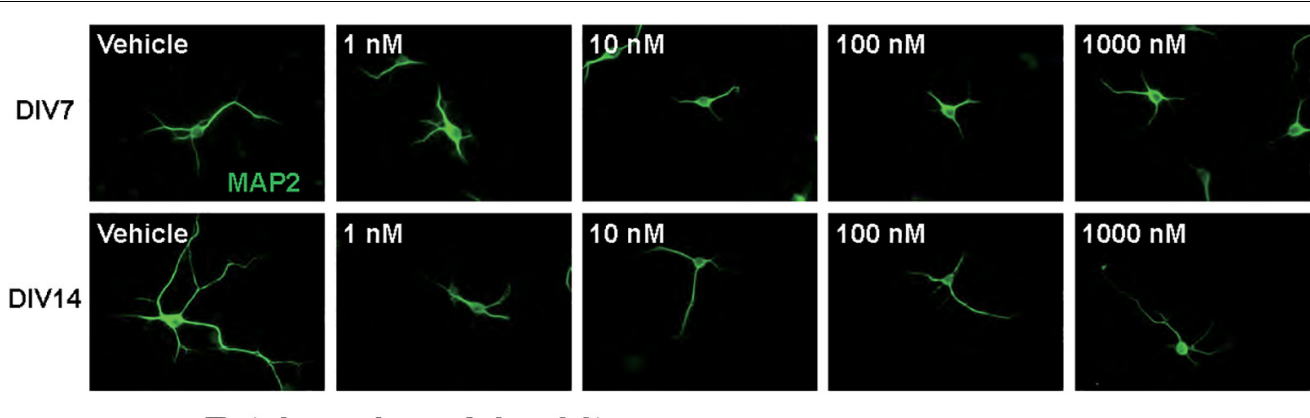

Total number of dendrites

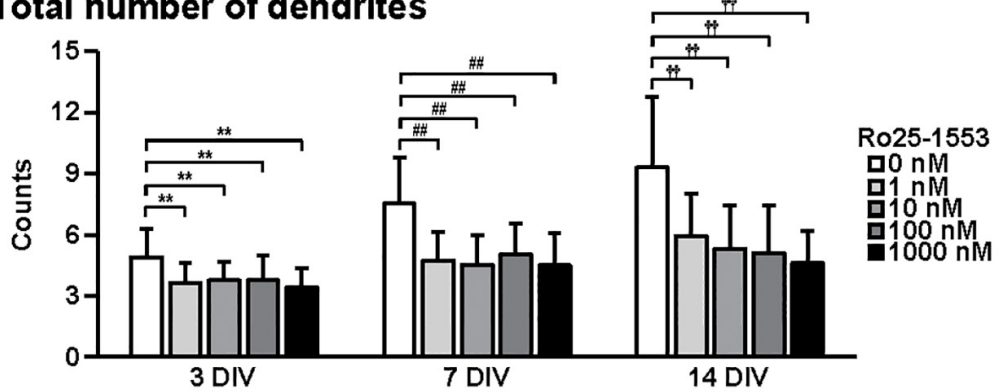

Total dendrite length

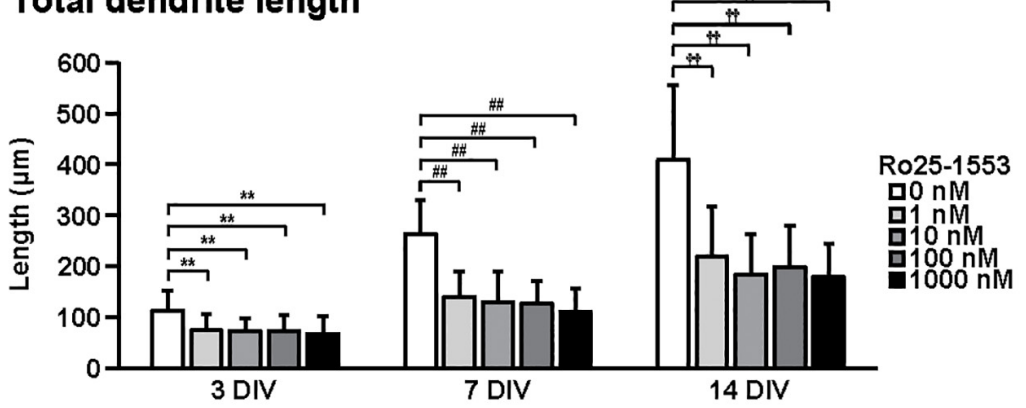

Dendritic complexity

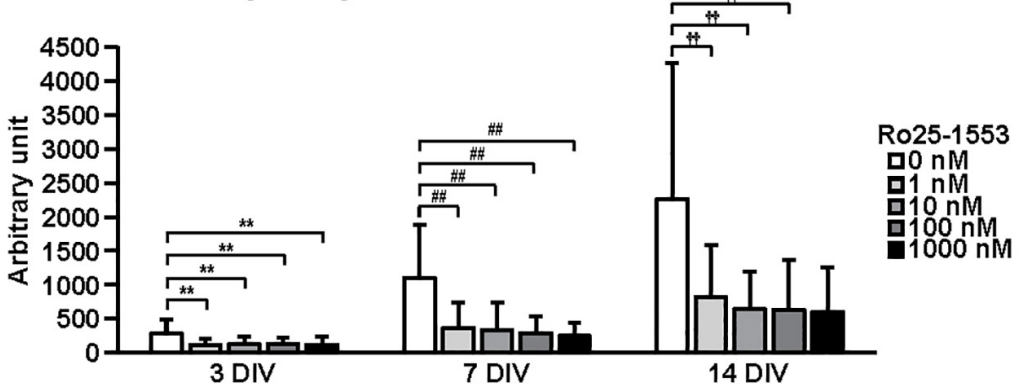

FIGURE 3 | Effects of Ro25-1553 on dendritic outgrowth in cultured cortical neurons. Representative MAP2 (green)-immunostained images of neurons cultured with Ro25-1553 (1-1000 nM) for 7 to 14 days in vitro (DIV) are shown. Quantitative analysis of dendritic morphology at 3 (Figure 1B), 7 , and 14 DIV revealed that Ro25-1553 significantly decreased the total numbers (main effects: $F_{2,805}=83.382, P<0.0001$ for time, $F_{4,805}=75.612, P<0.0001$ for treatment; interaction: $F_{8,805}=7.531, P<0.0001$ ) and length (main effects: $F_{2,805}=323.212, P<0.0001$ for time, $F_{4,805}=122.621, P<0.0001$ for treatment; interaction: $F_{8,805}=17.981, P<0.0001$ ) of dendrites, and dendritic complexity (main effects: $F_{2,805}=91.541, P<0.0001$ for time, $F_{4,805}=49.193, P<0.0001$ for treatment; interaction: $\left.F_{8,805}=11.777, P<0.0001\right)$. Values represent mean $\pm \mathrm{SD}$ of $40-60$ neurons from three independent experiments. ${ }^{\star \star} P<0.01$, ${ }^{\# \#} P<0.01,{ }^{\dagger \dagger} P<0.01$ vs. control.

numbers and length of dendrites, and dendritic complexity (Figure 6A). On the other hand, pretreatment with U0126, but not H89 or GF109203X, blocked PACAP (100 nM)-induced increases in total numbers and length of dendrites, and dendritic complexity (Figure 6B).

\section{DISCUSSION}

The present study confirmed that PAC1, VPAC1, and VPAC2 receptors are expressed in primary cultured mouse cortical neurons as observed in vivo mouse cortex (Marzagalli et al., 

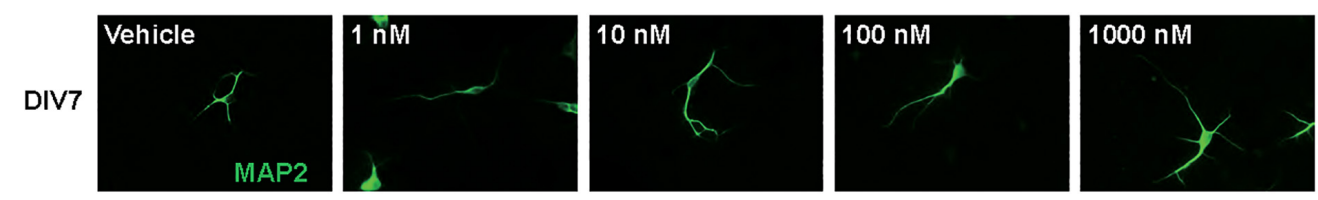

Total number of dendrites

Total dendrite length

PACAP
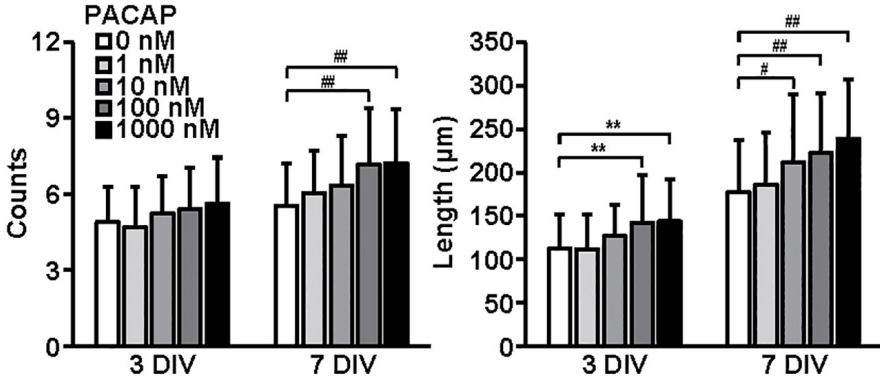

Dendritic complexity

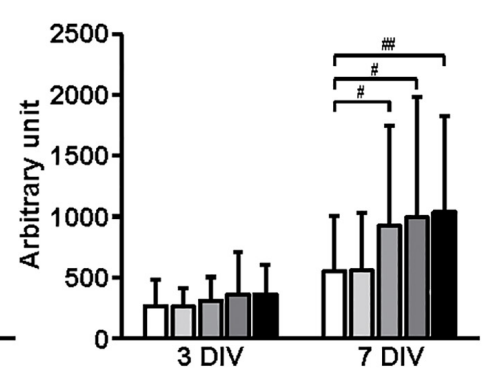

FIGURE 4 | Effects of PACAP on dendritic outgrowth in cultured cortical neurons. Representative MAP2 (green)-immunostained images of neurons cultured with PACAP (1-1000 nM) for 7 days in vitro (DIV) are shown. Quantitative analysis of dendritic morphology at 3 (Figure 1B) and 7 DIV revealed that PACAP dose-dependently increased the total numbers (main effects: $F_{1,510}=63.825, P<0.0001$ for time, $F_{4,510}=9.171, P<0.0001$ for treatment; interaction: $F_{4,510}=1.661, P>0.05$ ) and length (main effects: $F_{1,510}=231.606, P<0.0001$ for time, $F_{4,510}=12.279, P<0.0001$ for treatment; interaction: $F_{4,510}=0.957$, $P>0.05$ ) of dendrites, and dendritic complexity (main effects: $F_{1,510}=93.016, P<0.0001$ for time, $F_{4,510}=6.279, P<0.0001$ for treatment; interaction: $\left.F_{4,510}=2.822, P<0.05\right)$. Values represent mean \pm SD of $40-60$ neurons from three independent experiments. ${ }^{\star \star} P<0.01,{ }^{\#} P<0.05$, ${ }^{\# \#} P<0.01$ vs. control.

2016; Hirabayashi et al., 2018), indicating that Ro25-1553 and endogenous ligands VIP and PACAP could act through all VIP/PACAP receptors. We demonstrated that low concentrations (1-100 nM) of VIP and the VPAC2 receptor agonist Ro251553 reduced axon and dendritic outgrowth of cortical neural precursors measured at 3,7 , and 14 DIV. It is unlikely that the effects of Ro25-1553 and VIP on the numbers and complexity of axons and dendrites were due to general toxicity because the inhibitory effects of Ro25-1553 were abolished in VPAC2 receptor knockout mice (Figure 5B), and neither affected cell numbers based on the MTT [3-(4,5-dimethylthiazol2-yl)-2,5-diphenyltetrazolium bromide] assay (data not shown). Interestingly, the effect of VIP was lost at higher concentration (1 $\mu \mathrm{M})$, demonstrating a classical bell-shaped curve. This may be due to the fact that high dose of VIP can activate the PAC1 receptor (Drahushuk et al., 2002; Ogata et al., 2015), thereby producing an opposing effect which cancels the inhibitory action. On the other hand, PACAP, which binds with high affinity to PAC1 and VPAC2 receptors, promoted dendritic outgrowth of cortical neurons. In this context, the balance between VPAC2 receptor- and PAC1 receptor-mediated signals might be important to regulate the neurite outgrowth. However, we do not yet determine precisely why and how PACAP exhibits the opposite effect. To clarify this point, future studies on the effects of different concentrations of VIP and PACAP alone and in combination in either VPAC2- or PAC1-receptor knockout mice will be needed. Previously, Leemhuis et al. (2007) reported that VIP ( $1 \mathrm{nM})$ at 3 DIV for $18 \mathrm{~h}$ caused the increases in axon and dendritic outgrowth in cultured rat hippocampal neurons. This contrasts with the results of the present study using cortical neurons, again demonstrating that effects of these peptides are cell-type specific. Importantly, the effects of Ro25-1553 and VIP were blocked in the present study by pretreatment with a VPAC2 receptor antagonist PG99-465. Furthermore, we demonstrated the high specificity of the VPAC2 receptor agonist Ro25-1553, which was abolished in cortical neurons derived from VPAC2 receptor knockout mice. Overall, the results suggest that the activation of the VPAC2 receptor delays or limits the maturation in mouse cortical neurons. In a previous study, we also found that adult VPAC2 receptor knockout mice show abnormal dendritic morphology in the prelimbic and infralimbic cortices, but not basolateral amygdala (Ago et al., 2017). Loss of the VPAC2 receptor reorganized apical and basal dendritic arbors of prelimbic cortex neurons and apical, but not basal, dendritic arbors of infralimbic cortex neurons. In the prelimbic cortex neurons, the amount of apical dendritic material distal to the soma was decreased in VPAC2 receptor knockout mice, while proximal dendritic material was increased. In the infralimbic cortex, the amount of apical dendritic material proximal to the soma was increased in VPAC2 receptor knockout mice, while other indices of morphology did not differ. Although the present experimental design does not distinguish these regions, the findings suggest that the VPAC2 receptor plays an important role in regulating the development of dendritic morphology in the cerebral cortex. Like for PAC1 receptors, several splice variants of VPAC2 receptors in the mouse and human have been reported (Grinninger et al., 2004; Bokaei et al., 2006; Huang et al., 2006; Miller et al., 2006; Dickson and Finlayson, 2009) and there is a difference in the VPAC2 receptor expression level among brain regions (Sheward et al., 1995; Vertongen et al., 1997; Joo et al., 2004; Kalló et al., 2004; Marzagalli et al., 2016; Tian et al., 2019). These might explain at least partly the difference in the response to VIP in different neural cell types, but exact mechanisms remain 


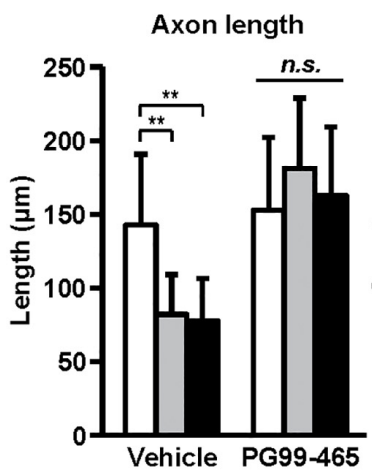

Total number of dendrites

Total dendrite length
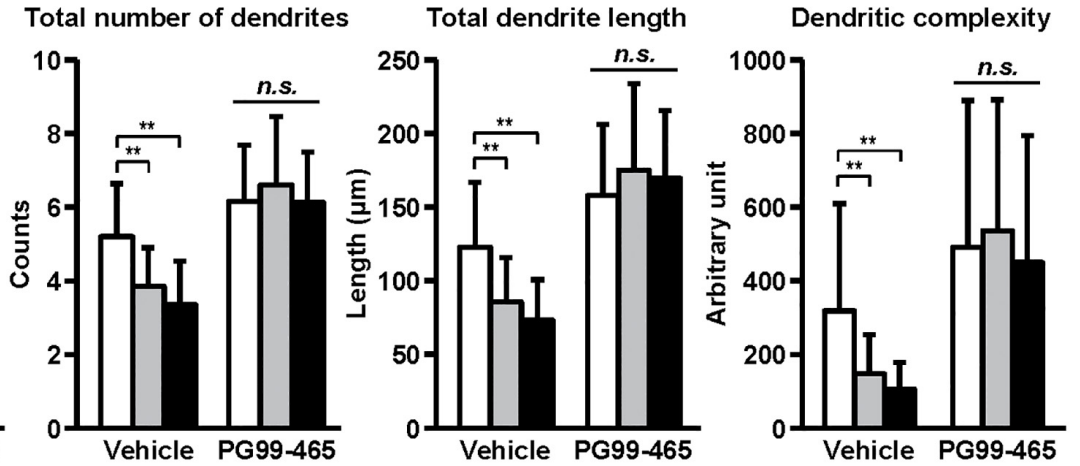

B VPAC2 receptor knockout mice

\section{DControl DRo25-1553}

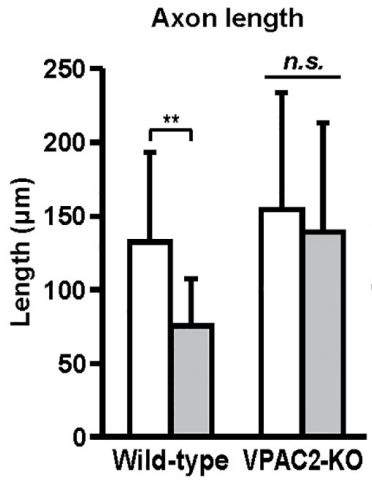

Total number of dendrites

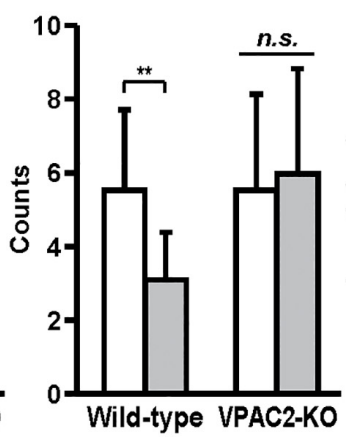

Total dendrite length

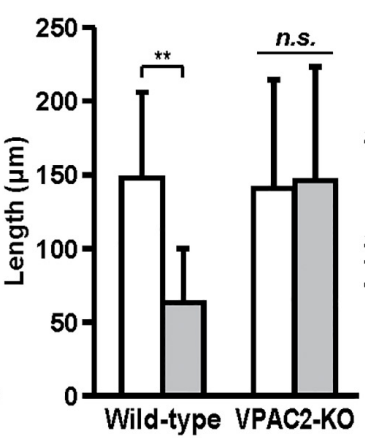

Dendritic complexity

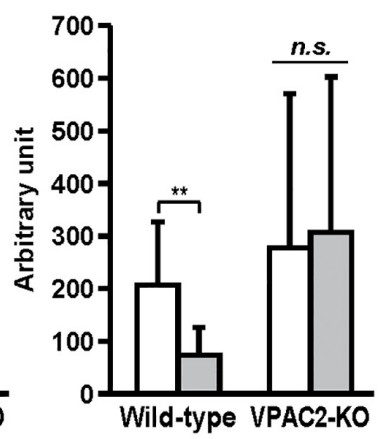

FIGURE 5 | VPAC2 receptor-mediated reductions in axon and dendritic outgrowth in cultured cortical neurons. Primary cortical neurons were cultured with Ro25-1553 (10 nM) or VIP (10 nM) for 3 days in vitro and double-immunostained for pNF and MAP2. (A) PG99-465 (100 nM) was treated 30 min before the treatment with Ro25-1553 or VIP. PG99-465 blocked Ro25-1553- and VIP-induced reductions in axon length (main effects: $F_{2,215}=8.338, P<0.001$ for Ro25-1553/NIP, $F_{1,215}=129.957, P<0.0001$ for PG99-465; interaction: $F_{2,215}=24.711, P<0.0001$ ), total numbers (main effects: $F_{2,215}=8.231, P<0.001$ for Ro25-1553/NIP, $F_{1,215}=127.826, P<0.0001$ for PG99-465; interaction: $F_{2,215}=10.525, P<0.0001$ ) and length (main effects: $F_{2,215}=3.701, P<0.05$ for Ro25-1553/NIP, $F_{1,215}=160.683, P<0.0001$ for PG99-465; interaction: $F_{2,215}=11.789, P<0.0001$ ) of dendrites, and dendritic complexity (main effects: $F_{2,215}=3.744, P<0.05$ for Ro25-1553/NIP, $F_{1,215}=61.073, P<0.0001$ for PG99-465; interaction: $\left.F_{2,215}=3.003, P<0.05\right)$. (B) Primary cortical neurons were prepared from VPAC2 receptor knockout (VPAC2-KO) mice and littermate wild-type mice. Ro25-1553-induced reductions in axon length (main effects: $F_{1,156}=12.655 P<0.001$ for treatment, $F_{1,156}=17.717, P<0.0001$ for genotype; interaction: $F_{1,156}=4.182, P<0.05$ ), total numbers (main effects: $F_{1,156}=7.274, P<0.01$ for treatment, $F_{1,156}=15.414, P<0.001$ for genotype; interaction: $F_{1,156}=15.414, P<0.001$ ) and length (main effects: $F_{1,156}=15.814$, $P<0.001$ for treatment, $F_{1,156}=14.262, P<0.001$ for genotype; interaction: $F_{1,156}=20.342, P<0.0001$ ) of dendrites, and dendritic complexity (main effects: $F_{1,156}=2.175, P>0.05$ for treatment, $F_{1,156}=19.468, P<0.0001$ for genotype; interaction: $\left.F_{1,156}=5.576, P<0.05\right)$ were abolished in cortical neurons derived from VPAC2-KO mice. Values represent mean $\pm S D$ of 40 neurons from three independent experiments. ${ }^{\star \star} P<0.01$ vs. control, n.S.; not significant.

unknown. It would be intriguing to examine whether activation of the VPAC2 receptor affects axon and dendritic outgrowth in different cell types.

Regarding the mechanism underlying the inhibitory effects of Ro25-1553 on cortical neuronal maturation, we found that a PKA inhibitor H89, but not a PKC inhibitor GF109203X or a MEK inhibitor U0126, prevented Ro25-1553-induced impairment of axon and dendritic outgrowth. This suggests that activation of the cAMP/PKA signaling pathway is involved in the VPAC2 receptor-induced impairment of axon and dendritic outgrowth. On the other hand, the opposing stimulatory effects of PACAP on dendritic outgrowth were blocked by U0126, but not H89 or GF109203X. Interestingly, PACAP38-induced
ERK phosphorylation and neuritogenesis was MEK-dependent and PKA-independent in PC12-derived Neuroscreen-1 cells (Emery and Eiden, 2012). On the other hand, cAMP responsive element binding (CREB) phosphorylation induced by PACAP was blocked by H89 in these cells. These suggest that PACAP can stimulate two distinct and independent cAMP pathways. In contrast, Kambe and Miyata (2012) showed that PACAP at doses of 1 and $10 \mathrm{nM}$, but not $0.1 \mathrm{nM}$, increased neurite outgrowth in primary hippocampal neurons, and this effect was blocked by H89. Currently, the reason for the discrepancy about the involvement of PKA-mediated signaling in the effects of PACAP on neurite outgrowth is unknown. Together, these findings suggest that PACAP and VIP might have the diverse activities on 


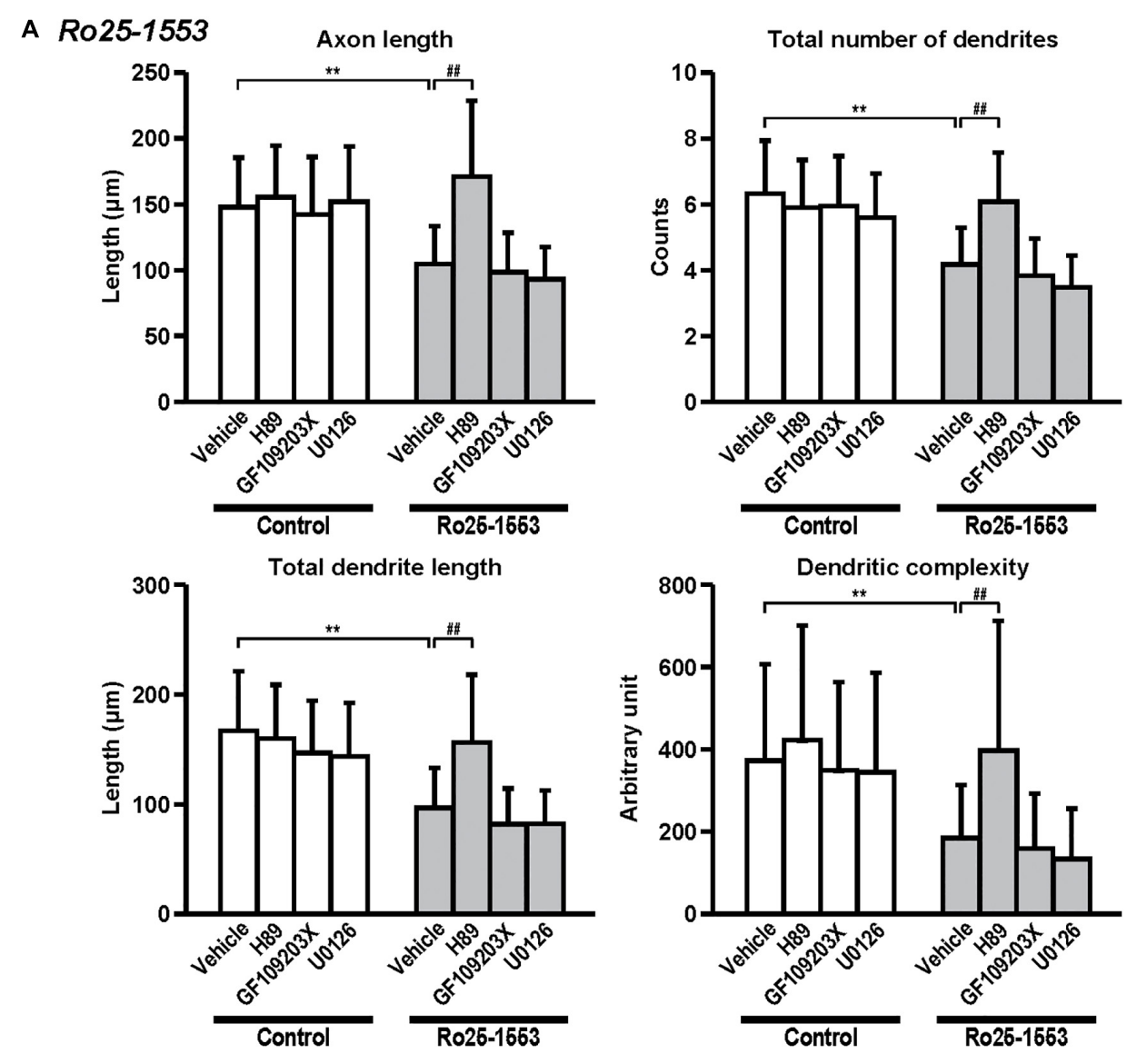

B PACAP

Total number of dendrites

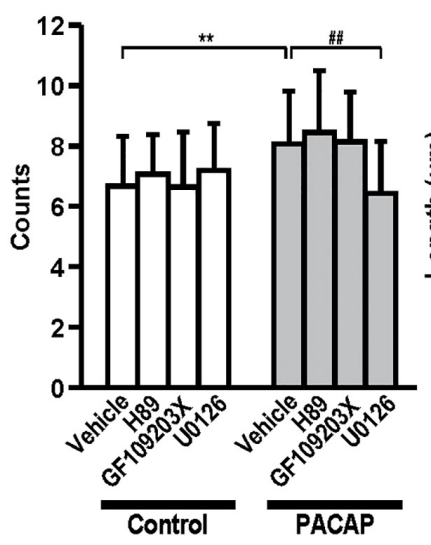

Total dendrite length

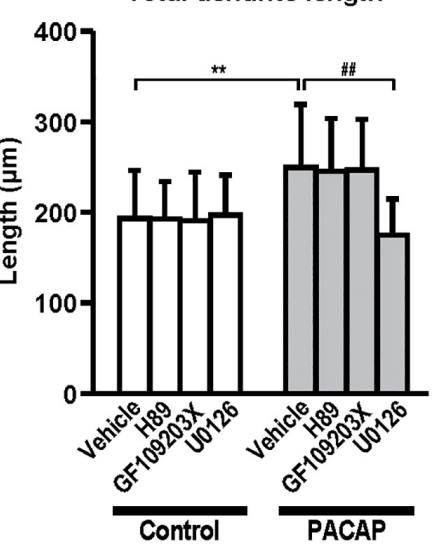

Dendritic complexity

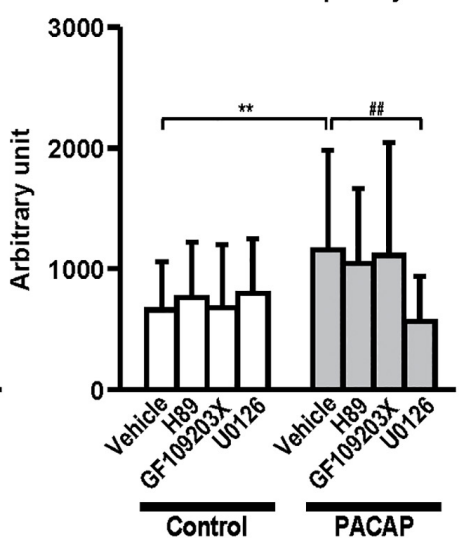

FIGURE 6 | Differential signaling pathways in the effects of Ro25-1553 and PACAP on axon and dendritic outgrowth. Primary cortical neurons were cultured with Ro25-1553 (10 nM) for 3 days in vitro (DIV) (A) or PACAP (100 nM) for 7 DIV (B) and double-immunostained for pNF and MAP2. H89 (1 $\mu$ M), GF109203X (1 $\mu$ M), or U0126 $(1 \mu \mathrm{M})$ was treated 30 min before the treatment with Ro25-1553 or PACAP. H89, but not GF109203X or U0126, blocked Ro25-1553-induced reductions in axon length (main effects: $F_{1,312}=55.022, P<0.0001$ for Ro25-1553, $F_{3,312}=21.421, P<0.0001$ for inhibitors; interaction: $F_{3,312}=14.153, P<0.0001$ ), total numbers (main effects: $F_{1,312}=107.531, P<0.0001$ for Ro25-1553, $F_{3,312}=17.086, P<0.0001$ for inhibitors; interaction: $F_{3,312}=14.788, P<0.0001$ ) and length (main effects: $F_{1,312}=93.817, P<0.0001$ for Ro25-1553, $F_{3,312}=16.605, P<0.0001$ for inhibitors; interaction: $F_{3,312}=9.139, P<0.0001$ ) of dendrites, and dendritic complexity (main effects: $F_{1,312}=39.122, P<0.0001$ for Ro25-1553, $F_{3,312}=10.089, P<0.0001$ for inhibitors; interaction: $F_{3,312}=3.091$, $P<0.05$ ). On the other hand, U0126, but not H89 or GF109203X, blocked PACAP-induced increases in total numbers (main effects: $F_{1,352}=23.759, P<0.001$ for PACAP, $F_{3,352}=4.738, P<0.01$ for inhibitors; interaction: $F_{3,352}=9.465, P<0.0001$ ) and length (main effects: $F_{1,352}=41.061, P<0.001$ for PACAP, $F_{3,352}=9.241, P<0.0001$ for inhibitors; interaction: $F_{3,352}=12.141, P<0.0001$ ) of dendrites, and dendritic complexity (main effects: $F_{1,352}=14.664, P<0.001$ for PACAP, $F_{3,352}=2.967, P<0.05$ for inhibitors; interaction: $\left.F_{3,352}=6.756, P<0.001\right)$. Values represent mean $\pm S D$ of $40-45$ neurons from three independent experiments. ${ }^{\star \star} P<0.01$ vs. control, ${ }^{\#} P<0.01$ vs. vehicle. 
neurite outgrowth via the distinct signaling pathway in different brain regions.

The impetus for our studies were the series of reports showing that micro-multiplications of the VIPR2 gene is associated with schizophrenia (Levinson et al., 2011; Vacic et al., 2011; Yuan et al., 2014; Li et al., 2016; Marshall et al., 2017) and ASD (Vacic et al., 2011; Firouzabadi et al., 2017), and that these mutations were associated in patients with heightened VIPinduced cAMP responsiveness (Vacic et al., 2011). hVIPR2-BAC tg mice were recently shown to exhibit multiple psychiatric disorder-related behavioral phenotypes and early postnatal striatal developmental deficits that manifested as the elevated cAMP/PKA signaling, increased striatal excitatory inputs, and striatal dendritic maturation deficit (Tian et al., 2019). We also found that pharmacological activation of the VPAC2 receptor in the mouse during early postnatal development caused prepulse inhibition deficits and reductions in synaptic proteins synaptophysin and PSD-95 in the prefrontal cortex (Ago et al., 2015). Impairments of dendritic and synaptic density in pyramidal neurons across multiple brain regions, such as changes in dendritic arborization, dendritic spine number/type, and morphology, have been observed in schizophrenia (Moyer et al., 2015). In particular, reduced length of basilar dendrites and reduced dendritic number have been found in layer 3 in the prefrontal cortical areas (Brodmann area (BA) 10, BA 11, and BA 46), anterior cingulate cortex (BA 32) of schizophrenic patients (Glantz and Lewis, 2000; Kalus et al., 2000; Broadbelt et al., 2002; Black et al., 2004; Konopaske et al., 2014). VIP has been known to be highly expressed in the layer $2 / 3$ inhibitory interneurons, and thus VIP neurons control neocortical activity (Tremblay et al., 2016). Taken together, the present in vitro study suggests that the activation of the VPAC2 receptor directly disrupts cortical neuronal maturation and implies that the VIPR2 linkage can be explained in part by impaired neuronal maturation due to overactivity of VPAC2 receptors at a time of brain development when neural circuits involved in cognition and social behavior are being established and/or that VPAC2 receptor overactivity disrupts ongoing synaptic plasticity in the adult brain.

\section{DATA AVAILABILITY STATEMENT}

The datasets generated for this study are available on reasonable request to the corresponding author.

\section{REFERENCES}

Ago, Y., Condro, M. C., Tan, Y. V., Ghiani, C. A., Colwell, C. S., Cushman, J. D., et al. (2015). Reductions in synaptic proteins and selective alteration of prepulse inhibition in male C57BL/6 mice after postnatal administration of a VIP receptor (VIPR2) agonist. Psychopharmacology (Berl.) 232, 2181-2189. doi: 10.1007/s00213-014-3848-z

Ago, Y., Hayata-Takano, A., Kawanai, T., Yamauchi, R., Takeuchi, S., Cushman, J. D., et al. (2017). Impaired extinction of cued fear memory and abnormal dendritic morphology in the prelimbic and infralimbic cortices in VPAC2 receptor (VIPR2)-deficient mice. Neurobiol. Learn. Mem. 145, 222-231. doi: 10.1016/j.nlm.2017.10.010

\section{ETHICS STATEMENT}

All animal studies were approved by the Animal Research Committee at University of California, Los Angeles (UCLA) and the Animal Care and Use Committee of the Graduate School of Pharmaceutical Sciences, Osaka University, and the Graduate School of Biomedical and Health Sciences, Hiroshima University. All experimental procedures were conducted in accordance with the guidelines of the Guide for the Care and Use of Laboratory Animals (National Research Council, 1996). Every effort was made to minimize animal suffering, and to reduce the number of animals used.

\section{AUTHOR CONTRIBUTIONS}

ST, TK, RY, LC, TM, MY, SA, AH-T, and YA performed the experiments and analyzed the data. TN, KY, NH, SN, KT, JW, $\mathrm{HH}$, and YA supported the study, designed study, and wrote the manuscript. $\mathrm{HH}$ and YA reviewed and approved the manuscript and held all the responsibilities related to this manuscript. All authors reviewed and approved the manuscript.

\section{FUNDING}

This study was supported in part by grants from the National Institutes of Health, grant numbers MH098506 and HD04612 to JW, Simons Foundation to JW, the JSPS Program for Advancing Strategic International Networks to Accelerate the Circulation of Talented Researchers (S2603; HH), JSPS KAKENHI, grant numbers JP15H04645 and JP18H02574 to TN, JP17K19488 and JP17H03989 to HH, JP16K08268 and JP20H03392 to YA, MEXT KAKENHI, grant numbers JP19H04909 and JP19H05218 to TN, and JP18H05416 to HH, AMED, grant numbers JP19gm1310003 to TN, JP19dm0107122 and JP19dm0207061 to HH, grants from the Takeda Science Foundation to $\mathrm{HH}$ and YA, the Mochida Memorial Foundation for Medical and Pharmaceutical Research to YA, the Pharmacological Research Foundation, Tokyo, to YA. This research was also partially supported by collaborative research between Osaka University and Shionogi \& Co., Ltd (PHarma-INnovation Discovery competition Shionogi, to YA) and AMED under grant number JP19am0101084 (Kazutake Tsujikawa, Ph.D., Graduate School of Pharmaceutical Sciences, Osaka University).

Black, J. E., Kodish, I. M., Grossman, A. W., Klintsova, A. Y., Orlovskaya, D., Vostrikov, V., et al. (2004). Pathology of layer $\mathrm{V}$ pyramidal neurons in the prefrontal cortex of patients with schizophrenia. Am. J. Psychiatry 161, 742-744. doi: 10.1176/appi.ajp.161. 4.742

Bokaei, P. B., Ma, X. Z., Byczynski, B., Keller, J., Sakac, D., Fahim, S., et al. (2006). Identification and characterization of five-transmembrane isoforms of human vasoactive intestinal peptide and pituitary adenylate cyclase-activating polypeptide receptors. Genomics 88, 791-800. doi: 10.1016/j.ygeno.2006. 07.008

Broadbelt, K., Byne, W., and Jones, L. B. (2002). Evidence for a decrease in basilar dendrites of pyramidal cells in schizophrenic medial prefrontal 
cortex. Schizophr. Res. 58, 75-81. doi: 10.1016/s0920-9964(02)00 201-3

Deshpande, A., and Weiss, L. A. (2018). Recurrent reciprocal copy number variants: roles and rules in neurodevelopmental disorders. Dev. Neurobiol. 78, 519-530. doi: 10.1002/dneu.22587

Deutsch, P. J., Schadlow, V. C., and Barzilai, N. (1993). 38-Amino acid form of pituitary adenylate cyclase activating peptide induces process outgrowth in human neuroblastoma cells. J. Neurosci. Res. 35, 312-320. doi: 10.1002/jnr. 490350311

Deutsch, P. J., and Sun, Y. (1992). The 38-amino acid form of pituitary adenylate cyclase-activating polypeptide stimulates dual signaling cascades in PC12 cells and promotes neurite outgrowth. J. Biol. Chem. 267, 5108-5113.

DiCicco-Bloom, E., Deutsch, P. J., Maltzman, J., Zhang, J., Pintar, J. E., Zheng, J., et al. (2000). Autocrine expression and ontogenetic functions of the PACAP ligand/receptor system during sympathetic development. Dev. Biol. 219, 197213. doi: $10.1006 /$ dbio. 2000.9604

Dickson, L., and Finlayson, K. (2009). VPAC and PAC receptors: from ligands to function. Pharmacol. Ther. 121, 294-316. doi: 10.1016/j.pharmthera.2008.11. 006

Drahushuk, K., Connell, T. D., and Higgins, D. (2002). Pituitary adenylate cyclaseactivating polypeptide and vasoactive intestinal peptide inhibit dendritic growth in cultured sympathetic neurons. J. Neurosci. 22, 6560-6569. doi: 10. 1523/JNEUROSCI.22-15-06560.2002

Emery, A. C., and Eiden, L. E. (2012). Signaling through the neuropeptide GPCR $\mathrm{PAC}_{1}$ induces neuritogenesis via a single linear CAMP- and ERK-dependent pathway using a novel cAMP sensor. FASEB J. 26, 3199-3211. doi: 10.1096/fj. 11-203042

Falluel-Morel, A., Chafai, M., Vaudry, D., Basille, M., Cazillis, M., Aubert, N., et al. (2007). The neuropeptide pituitary adenylate cyclase-activating polypeptide exerts anti-apoptotic and differentiating effects during neurogenesis: focus on cerebellar granule neurones and embryonic stem cells. J. Neuroendocrinol. 19, 321-327. doi: 10.1111/j.1365-2826.2007.01537.x

Falluel-Morel, A., Vaudry, D., Aubert, N., Galas, L., Benard, M., Basille, M., et al. (2005). Pituitary adenylate cyclase-activating polypeptide prevents the effects of ceramides on migration, neurite outgrowth, and cytoskeleton remodeling. Proc. Natl. Acad. Sci. U.S.A. 102, 2637-2642. doi: 10.1073/pnas.0409681102

Firouzabadi, S. G., Kariminejad, R., Vameghi, R., Darvish, H., Ghaedi, H., Banihashemi, S., et al. (2017). Copy number variants in patients with autism and additional clinical features: report of VIPR2 duplication and a novel microduplication syndrome. Mol. Neurobiol. 54, 7019-7027. doi: 10.1007/ s12035-016-0202-y

Foley, C., Corvin, A., and Nakagome, S. (2017). Genetics of schizophrenia: ready to translate? Curr. Psychiatry Rep. 19:61. doi: 10.1007/s11920-017-0807-5

Fukiage, C., Nakajima, T., Takayama, Y., Minagawa, Y., Shearer, T. R., and Azuma, M. (2007). PACAP induces neurite outgrowth in cultured trigeminal ganglion cells and recovery of corneal sensitivity after flap surgery in rabbits. Am. J. Ophthalmol. 143, 255-262. doi: 10.1016/j.ajo.2006.10.034

Glantz, L. A., and Lewis, D. A. (2000). Decreased dendritic spine density on prefrontal cortical pyramidal neurons in schizophrenia. Arch. Gen. Psychiatry 57, 65-73. doi: 10.1001/archpsyc.57.1.65

Gonzalez, B. J., Basille, M., Vaudry, D., Fournier, A., and Vaudry, H. (1997). Pituitary adenylate cyclase-activating polypeptide promotes cell survival and neurite outgrowth in rat cerebellar neuroblasts. Neuroscience 78, 419-430. doi: 10.1016/s0306-4522(96)00617-3

Grinninger, C., Wang, W., Oskoui, K. B., Voice, J. K., and Goetzl, E. J. (2004). A natural variant type II G protein-coupled receptor for vasoactive intestinal peptide with altered function. J. Biol. Chem. 279, 40259-40262. doi: 10.1074/ jbc.C400332200

Gourlet, P., Vertongen, P., Vandermeers, A., Vandermeers-Piret, M.-C., Rathe, J., De Neef, P., et al. (1997). The long-acting vasoactive intestinal polypeptide agonist RO $25-1553$ is highly selective of the $\mathrm{VIP}_{2}$ receptor subclass. Peptides 18, 403-408. doi: 10.1016/s0196-9781(96)00322-1

Harmar, A. J., Fahrenkrug, J., Gozes, I., Laburthe, M., May, V., Pisegna, J. R., et al. (2012). Pharmacology and functions of receptors for vasoactive intestinal peptide and pituitary adenylate cyclase-activating polypeptide: IUPHAR review 1. Br. J. Pharmacol. 166, 4-17. doi: 10.1111/j.1476-5381.2012.01871.x

Harmar, A. J., Marston, H. M., Shen, S., Spratt, C., West, K. M., Sheward, W. J., et al. (2002). The $\mathrm{VPAC}_{2}$ receptor is essential for circadian function in the mouse suprachiasmatic nuclei. Cell 109, 497-508. doi: 10.1016/s0092-8674(02)007365

Héraud, C., Hilairet, S., Muller, J. M., Leterrier, J. F., and Chadéneau, C. (2004). Neuritogenesis induced by vasoactive intestinal peptide, pituitary adenylate cyclase-activating polypeptide, and peptide histidine methionine in SH-SY5y cells is associated with regulated expression of cytoskeleton mRNAs and proteins. J. Neurosci. Res. 75, 320-329. doi: 10.1002/jnr.10866

Hernandez, A., Kimball, B., Romanchuk, G., and Mulholland, M. W. (1995). Pituitary adenylate cyclase-activating peptide stimulates neurite growth in PC1 2 cells. Peptides 16, 927-932. doi: 10.1016/0196-9781(95)00059-s

Hill, J. M. (2007). Vasoactive intestinal peptide in neurodevelopmental disorders: therapeutic potential. Curr. Pharm. Des. 13, 1079-1089. doi: 10.2174/ 138161207780618975

Hirabayashi, T., Nakamachi, T., and Shioda, S. (2018). Discovery of PACAP and its receptors in the brain. J. Headache Pain 19:28. doi: 10.1186/s10194-018-0855-1

Huang, M. C., Miller, A. L., Wang, W., Kong, Y., Paul, S., and Goetzl, E. J. (2006). Differential signaling of $\mathrm{T}$ cell generation of IL-4 by wild-type and shortdeletion variant of type $2 \mathrm{G}$ protein-coupled receptor for vasoactive intestinal peptide (VPAC2). J. Immunol. 176, 6640-6646. doi: 10.4049/jimmunol.176.11. 6640

Joo, K. M., Chung, Y. H., Kim, M. K., Nam, R. H., Lee, B. L., Lee, K. H., et al. (2004). Distribution of vasoactive intestinal peptide and pituitary adenylate cyclaseactivating polypeptide receptors (VPAC1. VPAC2, and PAC1 receptor) in the rat brain. J. Comp. Neurol. 476, 388-413. doi: 10.1002/cne.20231

Kalló, I., Kalamatianos, T., Piggins, H. D., and Coen, C. W. (2004). Ageing and the diurnal expression of mRNAs for vasoactive intestinal peptide and for the VPAC2 and PAC1 receptors in the suprachiasmatic nucleus of male rats. $J$. Neuroendocrinol. 16, 758-766. doi: 10.1111/j.1365-2826.2004.01232.x

Kalus, P., Müller, T. J., Zuschratter, W., and Senitz, D. (2000). The dendritic architecture of prefrontal pyramidal neurons in schizophrenic patients. Neuroreport 11,3621-3625. doi: 10.1097/00001756-200011090-00044

Kambe, Y., and Miyata, A. (2012). Role of mitochondrial activation in PACAP dependent neurite outgrowth. J. Mol. Neurosci. 48, 550-557. doi: 10.1007/ s12031-012-9754-0

Kawanai, T., Ago, Y., Watanabe, R., Inoue, A., Taruta, A., Onaka, Y., et al. (2016). Prenatal exposure to histone deacetylase inhibitors affects gene expression of autism-related molecules and delays neuronal maturation. Neurochem. Res. 41, 2574-2584. doi: 10.1007/s11064-016-1969-y

Konopaske, G. T., Lange, N., Coyle, J. T., and Benes, F. M. (2014). Prefrontal cortical dendritic spine pathology in schizophrenia and bipolar disorder. JAMA Psychiatry 71, 1323-1331. doi: 10.1001/jamapsychiatry.2014.1582

Lazarovici, P., Jiang, H., and Fink, D. Jr. (1998). The 38-amino-acid form of pituitary adenylate cyclase-activating polypeptide induces neurite outgrowth in PC12 cells that is dependent on protein kinase $\mathrm{C}$ and extracellular signal-regulated kinase but not on protein kinase $A$, nerve growth factor receptor tyrosine kinase, p21(ras) G protein, and pp60(c-src) cytoplasmic tyrosine kinase. Mol. Pharmacol. 54, 547-558. doi: 10.1124/mol.54. 3.547

Leemhuis, J., Henle, F., and Meyer, D. K. (2007). VIP induces the elongation of dendrites and axons in cultured hippocampal neurons: role of microtubules. Peptides 28, 1700-1705. doi: 10.1016/j.peptides.2007.06.026

Levinson, D. F., Duan, J., Oh, S., Wang, K., Sanders, A. R., Shi, J., et al. (2011). Copy number variants in schizophrenia: confirmation of five previous findings and new evidence for 3q29 microdeletions and VIPR2 duplications. Am. J. Psychiatry 168, 302-316. doi: 10.1176/appi.ajp.2010.1006 0876

Li, Z., Chen, J., Xu, Y., Yi, Q., Ji, W., Wang, P., et al. (2016). Genome-wide analysis of the role of copy number variation in schizophrenia risk in Chinese. Biol. Psychiatry 80, 331-337. doi: 10.1016/j.biopsych.2015.11.012

Lu, N., Zhou, R., and DiCicco-Bloom, E. (1998). Opposing mitogenic regulation by PACAP in sympathetic and cerebral cortical precursors correlates with differential expression of PACAP receptor (PAC1-R) isoforms. J. Neurosci. Res. 53, 651-662. doi: 10.1002/(SICI)1097-4547(19980915)53:6\&lt;651::AIDJNR3\&gt;3.0.CO;2-4

Manecka, D. L., Mahmood, S. F., Grumolato, L., Lihrmann, I., and Anouar, Y. (2013). Pituitary adenylate cyclase-activating polypeptide (PACAP) promotes both survival and neuritogenesis in PC12 cells through activation of nuclear factor $\kappa \mathrm{B}(\mathrm{NF}-\kappa \mathrm{B})$ pathway: involvement of extracellular signal-regulated kinase 
(ERK), calcium, and c-REL. J. Biol. Chem. 288, 14936-14948. doi: 10.1074/jbc. M112.434597

Marshall, C. R., Howrigan, D. P., Merico, D., Thiruvahindrapuram, B., Wu, W., Greer, D. S., et al. (2017). Contribution of copy number variants to schizophrenia from a genome-wide study of 41,321 subjects. Nat. Genet. 49, 27-35. doi: 10.1038/ng.3725

Marzagalli, R., Leggio, G. M., Bucolo, C., Pricoco, E., Keay, K. A., Cardile, V., et al. (2016). Genetic blockade of the dopamine D3 receptor enhances hippocampal expression of PACAP and receptors and alters their cortical distribution. Neuroscience 316, 279-295. doi: 10.1016/j.neuroscience.2015.12.034

Miller, A. L., Verma, D., Grinninger, C., Huang, M. C., and Goetzl, E. J. (2006). Functional splice variants of the type II G protein-coupled receptor (VPAC2) for vasoactive intestinal peptide in mouse and human lymphocytes. Ann. N. Y. Acad. Sci. 1070, 422-426. doi: 10.1196/annals.1317.055

Monaghan, T. K., Mackenzie, C. J., Plevin, R., and Lutz, E. M. (2008). PACAP-38 induces neuronal differentiation of human SH-SY5Y neuroblastoma cells via cAMP-mediated activation of ERK and p38 MAP kinases. J. Neurochem. 104, 74-88. doi: 10.1111/j.1471-4159.2007.05018.x

Moyer, C. E., Shelton, M. A., and Sweet, R. A. (2015). Dendritic spine alterations in schizophrenia. Neurosci. Lett. 601, 46-53. doi: 10.1016/j.neulet.2014.11.042

Muller, J. M., Philippe, M., Chevrier, L., Héraud, C., Alleaume, C., and Chadéneau, C. (2006). The VIP-receptor system in neuroblastoma cells. Regul. Pept. 137, 34-41. doi: 10.1016/j.regpep.2006.06.014

National Research Council (1996). Guide for the Care and Use of Laboratory Animals. Washington, DC: National Academy Press, doi: 10.17226/5140

Nelson, K. B., Grether, J. K., Croen, L. A., Dambrosia, J. M., Dickens, B. F., Jelliffe, L. L., et al. (2001). Neuropeptides and neurotrophins in neonatal blood of children with autism or mental retardation. Ann. Neurol. 49, 597-606. doi: 10.1002/ana.1024

Nicot, A., and DiCicco-Bloom, E. (2001). Regulation of neuroblast mitosis is determined by PACAP receptor isoform expression. Proc. Natl. Acad. Sci. U.S.A. 98, 4758-4763. doi: 10.1073/pnas.071465398

Ogata, K., Shintani, N., Hayata-Takano, A., Kamo, T., Higashi, S., Seiriki, K., et al. (2015). PACAP enhances axon outgrowth in cultured hippocampal neurons to a comparable extent as BDNF. PLoS One 10:e0120526. doi: 10.1371/journal.pone. 0120526

Pillai, A. G., de Jong, D., Kanatsou, S., Krugers, H., Knapman, A., Heinzmann, J. M., et al. (2012). Dendritic morphology of hippocampal and amygdalar neurons in adolescent mice is resilient to genetic differences in stress reactivity. PLoS One 7:e38971. doi: 10.1371/journal.pone.0038971

Sakai, Y., Hashimoto, H., Shintani, N., Katoh, H., Negishi, M., Kawaguchi, C., et al. (2004). PACAP activates Racl and synergizes with NGF to activate ERK1/2, thereby inducing neurite outgrowth in PC12 cells. Brain Res. Mol. Brain Res. 123, 18-26. doi: 10.1016/j.molbrainres.2003.12.013

Sheward, W. J., Lutz, E. M., and Harmar, A. J. (1995). The distribution of vasoactive intestinal peptide 2 receptor messenger RNA in the rat brain and pituitary gland as assessed by in situ hybridization. Neuroscience 67, 409-418. doi: 10.1016/ 0306-4522(95)00048-n

Suh, J., Lu, N., Nicot, A., Tatsuno, I., and DiCicco-Bloom, E. (2001). PACAP is an anti-mitogenic signal in developing cerebral cortex. Nat. Neurosci. 4, 123-124. doi: $10.1038 / 83936$

Sullivan, P. F., Daly, M. J., and O’Donovan, M. (2012). Genetic architectures of psychiatric disorders: the emerging picture and its implications. Nat. Rev. Genet. 13, 537-551. doi: 10.1038/nrg3240

Takuma, K., Fang, F., Zhang, W., Yan, S., Fukuzaki, E., and Du, H. (2009). RAGEmediated signaling contributes to intraneuronal transport of amyloid- $\beta$ and neuronal dysfunction. Proc. Natl. Acad. Sci. U.S.A. 106, 20021-20026. doi: 10. 1073/pnas.0905686106
Tian, X., Richard, A., El-Saadi, M. W., Bhandari, A., Latimer, B., Van Savage, I., et al. (2019). Dosage sensitivity intolerance of VIPR2 microduplication is disease causative to manifest schizophrenia-like phenotypes in a novel BAC transgenic mouse model. Mol. Psychiatry 24, 1884-1901. doi: 10.1038/s41380-019-0492-3

Tremblay, R., Lee, S., and Rudy, B. (2016). GABAergic interneurons in the neocortex: from cellular properties to circuits. Neuron 91, 260-292. doi: 10. 1016/j.neuron.2016.06.033

Vacic, V., McCarthy, S., Malhotra, D., Murray, F., Chou, H. H., Peoples, A., et al. (2011). Duplications of the neuropeptide receptor gene VIPR2 confer significant risk for schizophrenia. Nature 471, 499-503. doi: 10.1038/ nature09884

Vaudry, D., Falluel-Morel, A., Bourgault, S., Basille, M., Burel, D., Wurtz, O., et al. (2009). Pituitary adenylate cyclase-activating polypeptide and its receptors: 20 years after the discovery. Pharmacol. Rev. 61, 283-357. doi: 10.1124/pr.109. 001370

Vaudry, D., Stork, P. J., Lazarovici, P., and Eiden, L. E. (2002). Signaling pathways for PC12 cell differentiation: making the right connections. Science 296, 16481649. doi: $10.1126 /$ science. 1071552

Vertongen, P., Schiffmann, S. N., Gourlet, P., and Robberecht, P. (1997). Autoradiographic visualization of the receptor subclasses for vasoactive intestinal polypeptide (VIP) in rat brain. Peptides 18, 1547-1554. doi: 10.1016/ s0196-9781(97)00229-5

Vicari, S., Napoli, E., Cordeddu, V., Menghini, D., Alesi, V., Loddo, S., et al. (2019). Copy number variants in autism spectrum disorders. Prog. Neuropsychopharmacol. Biol. Psychiatry 92, 421-427. doi: 10.1016/j.pnpbp. 2019.02.012

Waschek, J. A. (1996). VIP and PACAP receptor-mediated actions on cell proliferation and survival. Ann. N. Y. Acad. Sci. 805, 290-300. doi: 10.1111/j. 1749-6632.1996.tb17491.x

Waschek, J. A. (2002). Multiple actions of pituitary adenylyl cyclase activating peptide in nervous system development and regeneration. Dev. Neurosci. 24, 14-23. doi: 10.1159/000064942

White, D. M., and Mansfield, K. (1996). Vasoactive intestinal polypeptide and neuropeptide $\mathrm{Y}$ act indirectly to increase neurite outgrowth of dissociated dorsal root ganglion cells. Neuroscience 73, 881-887. doi: 10.1016/03064522(96)00055-3

White, D. M., Walker, S., Brenneman, D. E., and Gozes, I. (2000). CREB contributes to the increased neurite outgrowth of sensory neurons induced by vasoactive intestinal polypeptide and activity-dependent neurotrophic factor. Brain Res. 868, 31-38. doi: 10.1016/s0006-8993(00)02 259-9

Yuan, J., Jin, C., Sha, W., Zhou, Z., Zhang, F., Wang, M., et al. (2014). A competitive PCR assay confirms the association of a copy number variation in the VIPR2 gene with schizophrenia in Han Chinese. Schizophr. Res. 156, 66-70. doi: 10. 1016/j.schres.2014.04.004

Conflict of Interest: The authors declare that this study received funding from Shionogi \& Co., Ltd. The funder had the following involvement with the study: design of the study. KY and NH are full-time employees of Shionogi \& Co., Ltd.

Copyright (c) 2020 Takeuchi, Kawanai, Yamauchi, Chen, Miyaoka, Yamada, Asano, Hayata-Takano, Nakazawa, Yano, Horiguchi, Nakagawa, Takuma, Waschek, Hashimoto and Ago. This is an open-access article distributed under the terms of the Creative Commons Attribution License (CC BY). The use, distribution or reproduction in other forums is permitted, provided the original author(s) and the copyright owner(s) are credited and that the original publication in this journal is cited, in accordance with accepted academic practice. No use, distribution or reproduction is permitted which does not comply with these terms. 